\title{
Correction to: Characteristic of microplastics in the atmospheric fallout from Dongguan City, China: preliminary research and first evidence
}

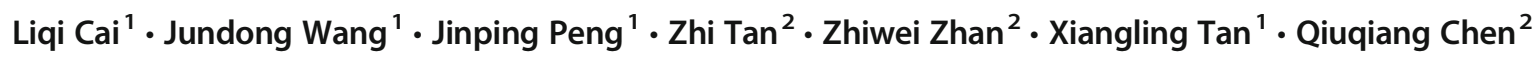

Published online: 14 November 2019

(C) Springer-Verlag GmbH Germany, part of Springer Nature 2019

Correction to: Environ Sci Pollut Res (2017) 24:24928-24935

https://doi.org/10.1007/S11356-017-0116-X

Unfortunately, the original version of this article contained two mistakes.

In the Fig. 3

The "Reference Cellulose" spectrum was misplaced in the original version. The correct "Reference Cellulose" spectrum as shown below

Jinping Peng

Jppeng@gdut.edu.cn

1 Faculty of Chemical Engineering and Light Industry, Guangdong

University of Technology, Guangzhou 510006, China

2 Dongguan Environmental Monitoring Central Station,

Dongguan 523009, China 


\section{Reference PE}

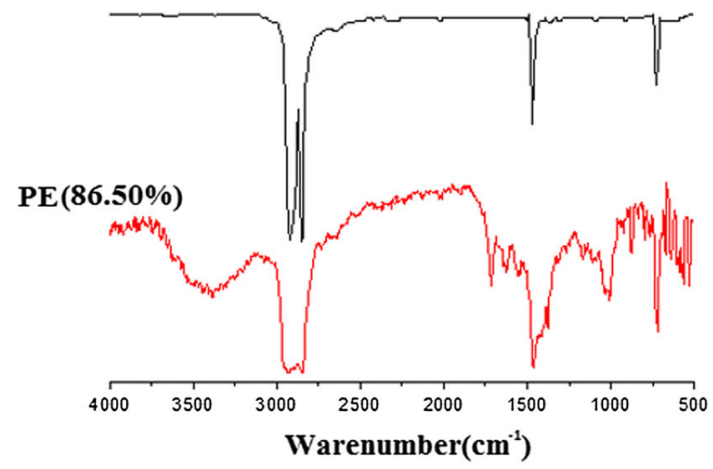

Reference Cellouse

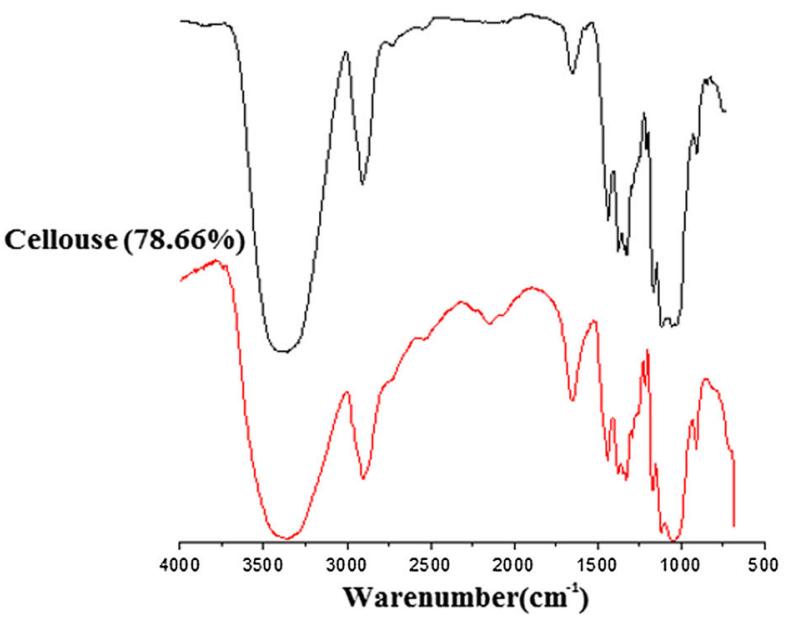

Reference PP

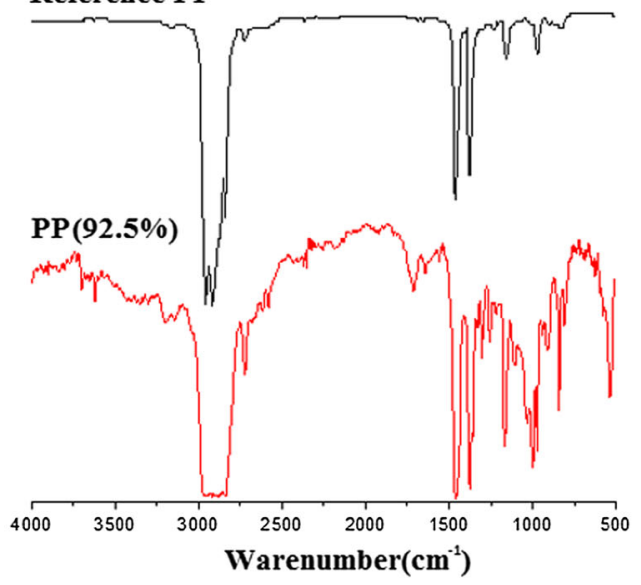

Reference PS

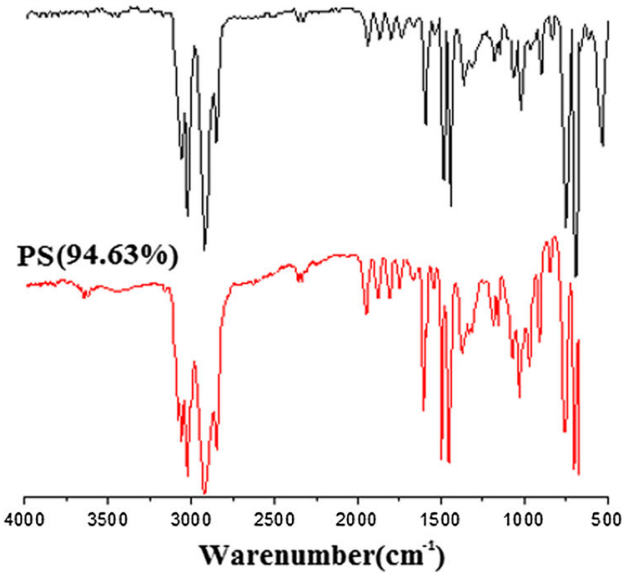

Fig. 3 FTIR spectra of identified polymers and the match degrees with the standard spectra

Abundance

The expression of "In contrast, the abundance of microplastics in the atmospheric fallout from Dongguan city is much closer to the urban site but smaller than the suburban site in Paris." was incorrect. The correct expression is "In contrast, the abundance of microplastics in the atmospheric fallout from Dongguan city is much closer to the urban site but lager than the suburban site in Paris."

Publisher's note Springer Nature remains neutral with regard to jurisdictional claims in published maps and institutional affiliations. 